\title{
Upregulation of p-Akt by glial cell line-derived neurotrophic factor ameliorates cell apoptosis in the hippocampus of rats with streptozotocin-induced diabetic encephalopathy
}

\author{
WEIGANG CUI $^{1}$, YINGHUA ZHANG ${ }^{1}$, DERONG LU $^{2}$, MINGXIN REN $^{1}$ and GUOYAN YUAN ${ }^{3}$ \\ ${ }^{1}$ Henan Key Laboratory of Medical Tissue Regeneration, Department of Human Anatomy, \\ Xinxiang Medical University, Xinxiang, Henan 453003; ${ }^{2}$ Department of Internal Digestive Medicine, \\ The Third Affiliated Hospital of Xinxiang Medical University, Xinxiang, Henan 453003; ${ }^{3}$ Department of Neurosurgery, \\ The First Affiliated Hospital, Xinxiang Medical University, Weihui, Henan 453100, P.R. China
}

Received November 12, 2014; Accepted September 22, 2015

DOI: $10.3892 / \mathrm{mmr} .2015 .4507$

\begin{abstract}
The loss of neurotrophic factor support has been shown to contribute to the development of the central nervous system. Glial cell line-derived neurotrophic factor (GDNF), a potent neurotrophic factor, is closely associated with apoptosis and exerts neuroprotective effects on numerous populations of cells. However, the underlying mechanisms of these protective effects remain unknown. In the present study, a significant increase in Bax levels and DNA fragmentation was observed in the hippocampus obtained from the brains of diabetic rats 60 days after diabetes had been induced. The apoptotic changes were correlated with the loss of GDNF/Akt signaling. GDNF administration was found to reverse the diabetes-induced Bax and DNA fragmentation changes. This was associated with an improvement in the level of p-Akt/Akt. In addition, combination of GDNF with a specific inhibitor of the phosphoinositide 3-kinase (PI3K)/Akt pathway, Wortmannin, significantly abrogated the effects of GDNF on the levels of p-Akt/Akt, Bax and DNA fragmentation. However, a p38 mitogen-activated proten kinase (MAPK) inhibitor, SB203580, had no effect on the expression of p-Akt/Akt, Bax or DNA fragmentation. These results demonstrate the pivotal role of GDNF as well as the PI3K/Akt pathway, but not the MAPK pathway, in the prevention of diabetes-induced neuronal apoptosis in the hippocampus.
\end{abstract}

Correspondence to: Dr Weigang Cui, Henan Key Laboratory of Medical Tissue Regeneration, Department of Human Anatomy, Xinxiang Medical University, 601 Jinsui Road, Xinxiang, Henan 453003, P.R. China

E-mail: cuiweigang1978@126.com

Key words: diabetic encephalopathy, glial cell line-derived neurotrophic factor, $\mathrm{p}-\mathrm{Akt}$, apoptosis

\section{Introduction}

Diabetes mellitus (DM) is a metabolic disorder and can cause several complications, such as cardiomyopathy, peripheral neuropathy and nephropathy. Evidence has demonstrated that DM can also cause dysfunction in the brain termed diabetic encephalopathy (DE), which is characterized by brain neurophysiological changes, neurobehavioral deficits and neuron loss (1-4). Studies regarding streptozotocin (STZ)-induced type-1 diabetes in mice have provided evidence demonstrating that apoptosis is associated with neuron loss $(5,6)$.

Glial cell line-derived neurotrophic factor (GDNF) is one of the most potent growth and survival factors for neuronal cells and dopaminergic neurons (7-10). A previous study demonstrated that GDNF administration ameliorated cell apoptosis in neurodegeneration (11). One recent study indicated that GDNF could rescue retinal cells from neurodegeneration at an early stage of diabetes (12). GDNF-epithelial growth factor receptor 1 (EGR1) pathway activation is critical in renal epithelial cell apoptosis and migration in diabetic renal embryopathy (13). In addition, GDNF, nestin and glial fibrillary acidic protein (GFAP)-positive reactive astrocytes appeared at an early stage in 6-hydroxydopamine-induced Parkinsonism in rats, which suggested the existence of endogenous neuroprotective mechanisms that act via the release of BDNF and GDNF from GFAP-positive immunoreactive astrocytes (14). However, one recent study indicated that GDNF treatment did not affect neuronal survival but another neurotrophic factor, neurotrophin 3 , was able to enhance the survival of enteric ganglion cells in $\mathrm{H}_{2} \mathrm{O}_{2}$-treated cultures (15).

A series of studies have explored the signal transduction processes of GDNF, which underlie the neuroprotective effects $(16,17)$. A recent study showed that the GDNF/mitogen-activated proten kinase (MAPK)/EGR-1 pathway is critical in renal epithelial cell apoptosis and migration in diabetic renal embryopathy (13). The pleiotropic function of GDNF has been found to control migration and neuronal differentiation of enteric ganglion precursors (18). High intracellular activation of GDNF downstream pathways triggers neuronal differentiation, while low-level activation of 
GDNF signaling is crucial for the maintenance of the progenitor state (18). In addition, the ERK/MAPK pathway, instead of the phosphoinositide 3-kinase/Akt (PI3K/Akt) pathway, was proposed to be the key endogenous neuroprotective mechanism, acting via the release of bone-derived neurotrophic factor (BDNF) and GDNF from nestin and GFAP-positive reactive astrocytes in the 6-hydroxydopamine-induced rat model of Parkinson's (14). Furthermore, a recent study demonstrated that mechanical and thermal hypersensitivity was correlated with the structural changes and loss of GDNF/ Akt signaling in injured limbs 7 days after chronic constrictive injury was induced. Intramuscular injection of adenovirus encoding GDNF could restore the protein level and activity of the GDNF/Akt signaling pathway in the sciatic nerve (19). Notably, GDNF increased Akt phosphorylation, lowered $\beta$-cell death, and raised glucose-induced insulin secretion in cultured human islets (20).

Although it was previously demonstrated that GDNF is important in decreasing apoptosis in cultured Muller cells during the early stages of diabetic retinopathy (21), the possible effect of GDNF and downstream PI3K/Akt signaling on apoptosis in diabetic encephalopathy remains unclear. In the present study, it was revealed that administration of GDNF markedly increased p-Akt levels and decreased Bax and DNA fragmentation levels in the hippocampus of rats with STZ-induced DE. These effects of GDNF most likely occurred via the activation of the PI3K/Akt signaling pathway.

\section{Materials and methods}

Induction of diabetes and DE. A total of 45 male Sprague-Dawley rats (age, $\sim 60$ days; weight, $250 \mathrm{~g}$ ) were obtained from the Research Animal Center of Henan Province (Zhengzhou, China). The animals were provided with ad libitum access to water and food under a 12:12 h light-dark cycle at $24^{\circ} \mathrm{C}$. All of the animal experiments were conducted in accordance with the National Institute of Health guidelines for the Care and Use of Laboratory Animals (22). The present study was approved by the ethics committee of the Xinxiang Medical University (Xinxiang, China). Type 1 diabetes was induced by a single intraperitoneal injection of STZ $(60 \mathrm{mg} / \mathrm{kg}$ body weight; Sigma-Aldrich, St. Louis, MO, USA) or 0.1 M citrate buffer vehicle (Beyotime Institute of Biotechnology, Shanghai, China) as previously described $(23,24)$. Fasting blood glucose concentrations were measured $72 \mathrm{~h}$ after STZ injection. Rats $(\mathrm{n}=35)$ with blood glucose levels $>11.1 \mathrm{mmol} / 1$ were considered to be diabetic (23). Rats $(n=5)$ with blood sugar levels $<11.1 \mathrm{mmol} / 1$ were excluded from the study. The 35 diabetic rats were divided into seven groups: Group 1 was untreated; group 2 was treated with GDNF; group 3 with vehicle $(10 \mu \mathrm{l}$ of $0.1 \mathrm{M}$ phosphate-buffered saline (PBS) administered to the left lateral cerebral ventricle); group 4 with GDNF + Wortmannin (Calbiochem; Merck Millipore, Darmstadt, Germany); group 5 with Wortmannin; group 6 with GDNF + SB203580 (Calbiochem); and group 7 with SB203580. A total of 60 days following injection of STZ, diabetic rat brain structural abnormalities and cognitive impairment was assessed using a Y-maze as previously described (24).
Intracerebroventricular administration of GDNF. Beginning 60 days after STZ injection, the animals were anesthetized using ketamine/xylazine (10:6.5 solution; $1.0 \mathrm{ml} / \mathrm{kg}$ intraperitoneally; Sigma-Aldrich), A total of three $100 \mu \mathrm{g}$ intracerebroventricular injections of human recombinant GDNF (Peprotech, Inc., Rocky Hill, NJ, USA) in $10 \mu \mathrm{l}$ of $0.1 \mathrm{M}$ PBS or an equal volume of vehicle were administered to the left lateral cerebral ventricle (AP-1.0, LM-2.0, DV-3.4) at a rate of $1 \mu \mathrm{l} / \mathrm{min}$ every 7 days according to the methods of a previous study (25). To evaluate the signaling pathway involved in the effect of GDNF on apoptosis in the hippocampus, $1 \mathrm{~h}$ prior to GDNF injection rats received an intracerebroventricular injection of the PI3K/Akt inhibitor, Wortmannin $(2.5 \mu \mathrm{M}, 10 \mu \mathrm{l})$, p38 MAPK inhibitor, SB203580 $(50 \mu \mathrm{M}, 10 \mu \mathrm{l})$, or vehicle.

GDNF ELISA detection. The rats were sacrificed with an overdose of barbiturates 3 days after the final injection, and the hippocampus was removed immediately. The preparation of hippocampus homogenates for GDNF detection was conducted as previously described (26). Briefly, the hippocampus was homogenized in the lysate buffer containing $0.1 \%$ Tween-20, $0.5 \%$ bovine serum albumin, $2 \mathrm{mM}$ EDTA in $1 \mathrm{X}$ PBS, and protease inhibitors (all Sigma-Aldrich) and centrifuged at $14,000 \times \mathrm{g}$ for $30 \mathrm{~min}$ at $4^{\circ} \mathrm{C}$. After centrifugation, the supernatant was collected. The levels of GDNF were quantified in duplicate using a GDNF ELISA kit (R\&D Systems, Minneapolis, MN, USA) according to the manufacturer's instructions.

Preparation of tissue lysates and western blot analysis. The hippocampal tissue samples were lysed in ice-cold radioimmunoprecipitation assay buffer (Roche Diagnostics, $\mathrm{GmbH}$, Mannheim, Germany) containing 1X PBS, 0.1\% SDS, $1 \%$ Nonidet P-40, $0.5 \%$ sodium deoxycholate, $1 \mathrm{mM}$ sodium orthovanadate and protease inhibitor cocktail (Sigma-Aldrich) to extract the protein. Samples were incubated for $30 \mathrm{~min}$ on ice, and then the protein lysates were centrifugated at $12,000 \mathrm{x} \mathrm{g}$ for $30 \mathrm{~min}$ to remove the pellets. For western blot analysis, equal quantities of protein lysates were separated on 5-15\% Bis-Tris gels (Invitrogen; Thermo Fisher Scientific, Inc., Waltham, MA, USA) and proteins were transferred onto $0.22-\mu \mathrm{m}$ polyvinylidene difluoride membranes (Invitrogen; Thermo Fisher Scientific, Inc.) electrophoretically. The membrane was blocked with $5 \%$ non-fat milk for $2 \mathrm{~h}$ at room temperature then incubated with the specific antibodies at $4^{\circ} \mathrm{C}$ overnight: Rabbit monoclonal anti-rat p-Akt $(1: 1,000$; cat. no. 13038; Cell Signaling Technology, Inc., Danvers, MA, USA), rabbit monoclonal anti-rat Akt (1:1,000; cat. no. 46855; Cell Signaling Technology, Inc.) and rabbit polyclonal anti-rat Bax (1:1,000; cat. no. ab7977; Abcam, Cambridge, MA, USA). After washing with $1 \mathrm{X}$ Tris-buffered saline with $0.05 \%$ Tween-20, membranes were incubated with horseradish peroxidase-conjugated secondary antibody (Pierce, Rockford, IL, USA) for $1 \mathrm{~h}$ at room temperature and immunoreactivity was visualized by enhanced chemiluminescence (Pierce).

Measurement of DNA fragmentation. DNA fragmentation was evaluated using the Cell Death Detection ELISAPLUS kit (Roche Diagnostics) according to the manufacturer's instructions. Briefly, the tissues were washed 
A

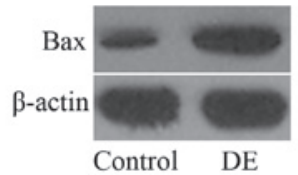

$21 \mathrm{kDa}$

$43 \mathrm{kDa}$

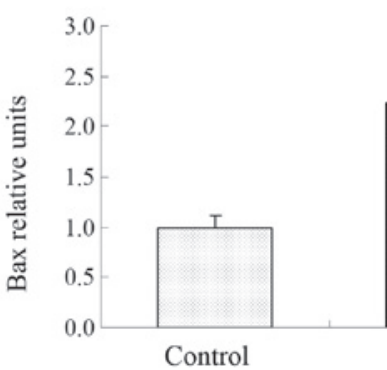

B

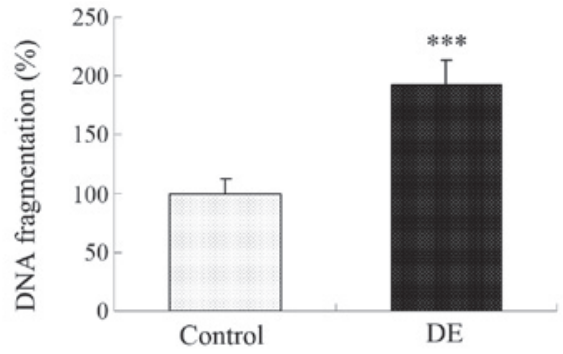

Figure 1. Expression of Bax and DNA fragmentation in hippocampus samples. The (A) expression of Bax and (B) DNA fragmentation were higher in rats with $\mathrm{DE}$ than in the control rats. Data are expressed as the mean \pm standard error of the mean, $\mathrm{n}=5$ for each group, ${ }^{* * *} \mathrm{P}<0.001$, compared with control subjects. $\mathrm{DE}$, diabetic encephalopathy.

A

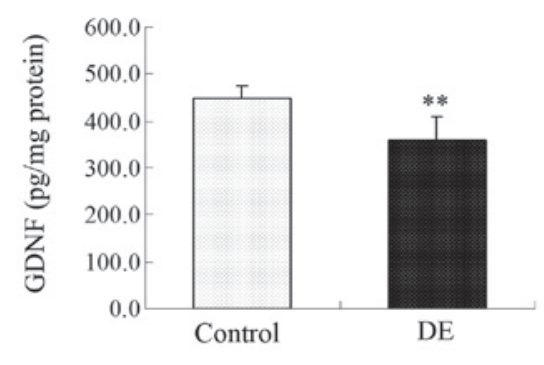

B
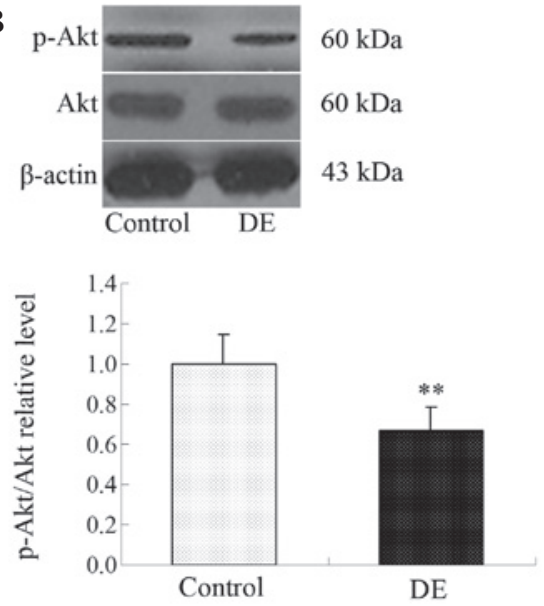

Figure 2. Detection of the GDNF and p-Akt/Akt levels in the hippocampus of diabetic rats. The expression of (A) GDNF and (B) p-Akt/Akt was decreased in the rats with DE compared with the control group. Data are expressed as the mean \pm standard error of the mean, $\mathrm{n}=5$ for each group, ${ }^{* *} \mathrm{P}<0.01$ compared with control. GDNF, glial cell line-derived neurotrophic factor; DE, diabetic encephalopathy.

with D-Hanks solution (Sigma-Aldrich), incubated with $200 \mu \mathrm{l}$ lysis buffer for $30 \mathrm{~min}$ at $37^{\circ} \mathrm{C}$ and centrifuged at $200 \mathrm{x} \mathrm{g}$ for $10 \mathrm{~min}$ at $4^{\circ} \mathrm{C}$. The supernatant from each tube was incubated in a microplate coated with streptavidin containing anti-DNA-peroxidase (1:50; clone MCA-33) and anti-histone-biotin (1:50; clone H11-4) to capture the apoptotic nucleosomes. Biotinylated mouse monoclonal anti-rat histone antibody bound via the histone component and the peroxidase-conjugated mouse monoclonal anti-rat DNA antibody bound to the DNA of the nucleosomes. The unbound antibodies were removed by washing with PBS, the amount of peroxidase retained within the immunocomplex was determined using 2,2'-azino-bis-3-ethylbenzthiazoline-6-sulfonic acid (Sigma-Aldrich). The absorbance was read at $405 \mathrm{~nm}$ using a microplate reader (CSL Behring, King of Prussia, PA, USA). The DNA fragmentation was defined as a percentage of the vehicle-treated group.

Statistical analysis. All data are presented as the mean \pm standard error of the mean, and statistical analysis was performed using one-way analysis of variance. The exact $\mathrm{F}$ statistic value and degrees of freedom were used to calculate probabilities. SPSS 16.0 (SPSS, Inc., Chicago, IL, USA) was used to conduct the statistical analyses. $\mathrm{P}<0.05$ was considered to indicate a statistically significant difference.

\section{Results}

Diabetes increases apoptosis in the hippocampus. In order to investigate whether or not apoptosis is induced in the hyppocampus, the level of Bax and DNA fragmentation in the hippocampus was examined. Following the induction of diabetes (60 days), a significant increase in apoptosis was observed in the rat hippocampi as compared with the control group. The data clearly shows that the levels of Bax (Fig. 1A) and DNA fragmentation (Fig. 1B) were significantly increased in the rats with DE compared with the control group.

STZ reduces the expression of GDNF and p-Akt/Akt level in the hippocampus of diabetic rats. To investigate whether 

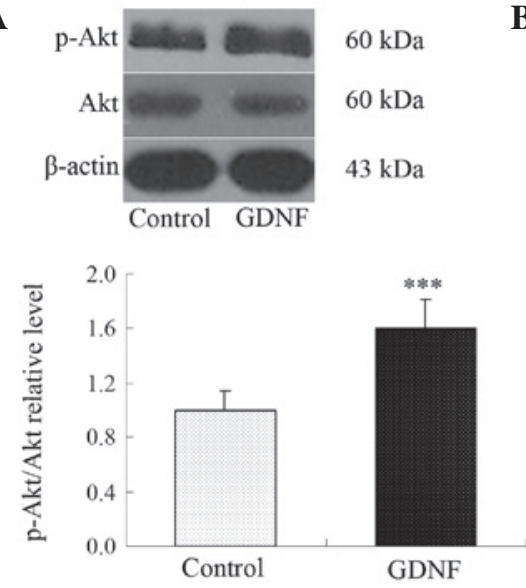

B
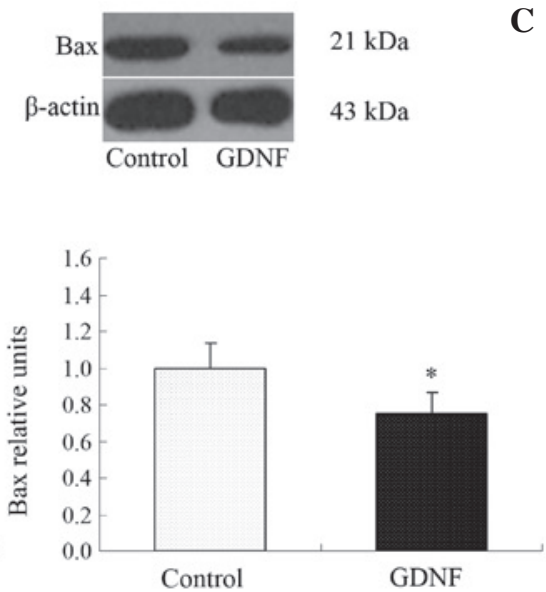

C

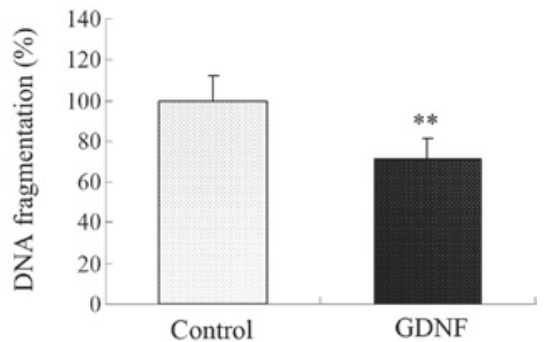

Figure 3. GDNF-affected p-Akt/Akt, Bax and DNA fragmentation levels in the hippocampus of rats with diabetic encephalopathy. The level of (A) p-Akt/ Akt was increased in the GDNF treatment group compared with the control group. The levels of (B) Bax and (C) DNA fragmentation were decreased in the GDNF treatment group compared with the vehicle-treated control group. Data are expressed as the mean \pm standard error of the mean, $\mathrm{n}=5$ per group, $\mathrm{P}<0.05$, ${ }^{* *} \mathrm{P}<0.01$ and ${ }^{* * * *} \mathrm{P}<0.001$ compared with the control. GDNF, glial cell line-derived neurotrophic factor.
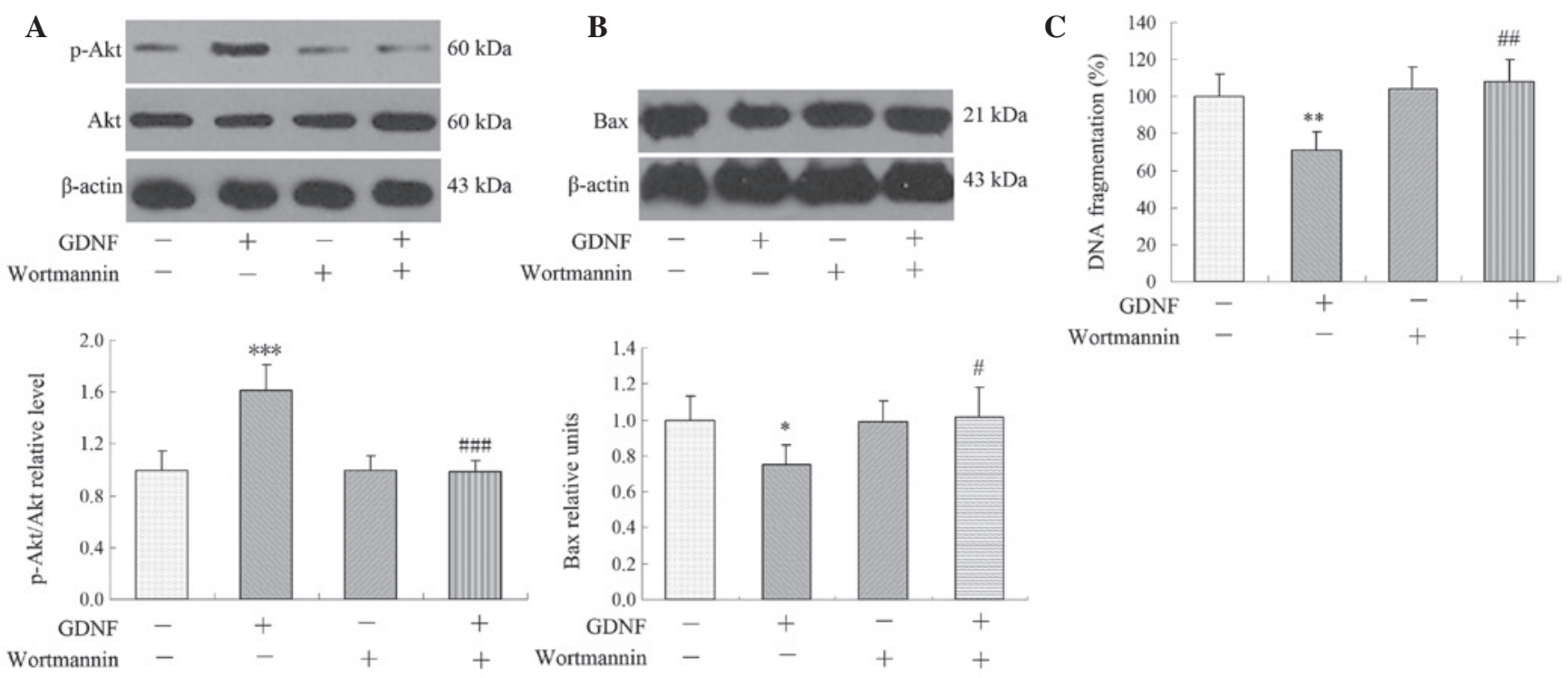

Figure 4. PI3K/Akt pathway was involved in GDNF-mediated effects on the level of p-Akt/Akt, Bax and DNA fragmentation. The PI3K/Akt inhibitor Wortmannin diminished the GDNF-induced change in (A) the level of p-Akt/Akt, (B) Bax expression and (C) DNA fragmentation following treatment with (+) or without (-) GDNF, Wortmannin, or both. Data are expressed as the mean \pm standard error of the mean, $n=5$ for each group, ${ }^{*} \mathrm{P}<0.05,{ }^{* *} \mathrm{P}<0.01$ and ${ }^{* * * *} \mathrm{P}<0.001$ compared with the vehicle-treated control group; ${ }^{\#} \mathrm{P}<0.05,{ }^{\# \#} \mathrm{P}<0.01$ and ${ }^{\# \# \#} \mathrm{P}<0.001$ compared with GDNF-treated group. PI3K, phosphoinositide 3-kinase; GDNF, glial cell line-derived neurotrophic factor.

GDNF signals are involved in DE, the protein level of GDNF was analyzed by ELISA 2 months after STZ administration. The expression of GDNF in the hippocampus was evidently lower in the STZ-induced group as compared with the control group (Fig. 2A). The expression of p-Akt/Akt, a downstream target of GDNF signals, was also significantly decreased in the hippocampus at day 60 in the rats with DE as compared with the control group (Fig. 2B).

GDNF delivery changes the expression of $p$-Akt/Akt and the apoptotic status in rats with DE. Effects of human recombinant GDNF administration on Akt levels in rats with DE were evaluated by western blot analysis. As shown in Fig. 3, the p-Akt/Akt level in the GDNF-treated rats was significantly increased compared with that of the control diabetic group, while the levels of Bax and DNA fragmentation in the GDNF-treated diabetic rats were largely reduced (Fig. 3).

PI3K/Akt inhibitor reverses GDNF-induced activation of $p$-Akt. The signaling pathway involved in GDNF-induced anti-apoptosis was then analyzed in the hippocampi of rats with DE. The PI3K/Akt inhibitor Wortmannin antagonized GDNF-induced p-Akt expression, and the levels of Bax and DNA fragmentation (Fig. 4A-C), while the p38 MAPK inhibitor SB203580 did not affect the level of p-Akt/Akt, Bax or DNA fragmentation (Fig. 5A-C). This suggested that the PI3K/Akt pathway but not the MAPK pathway, is involved in GDNF-induced Akt expression in the hippocampus. 

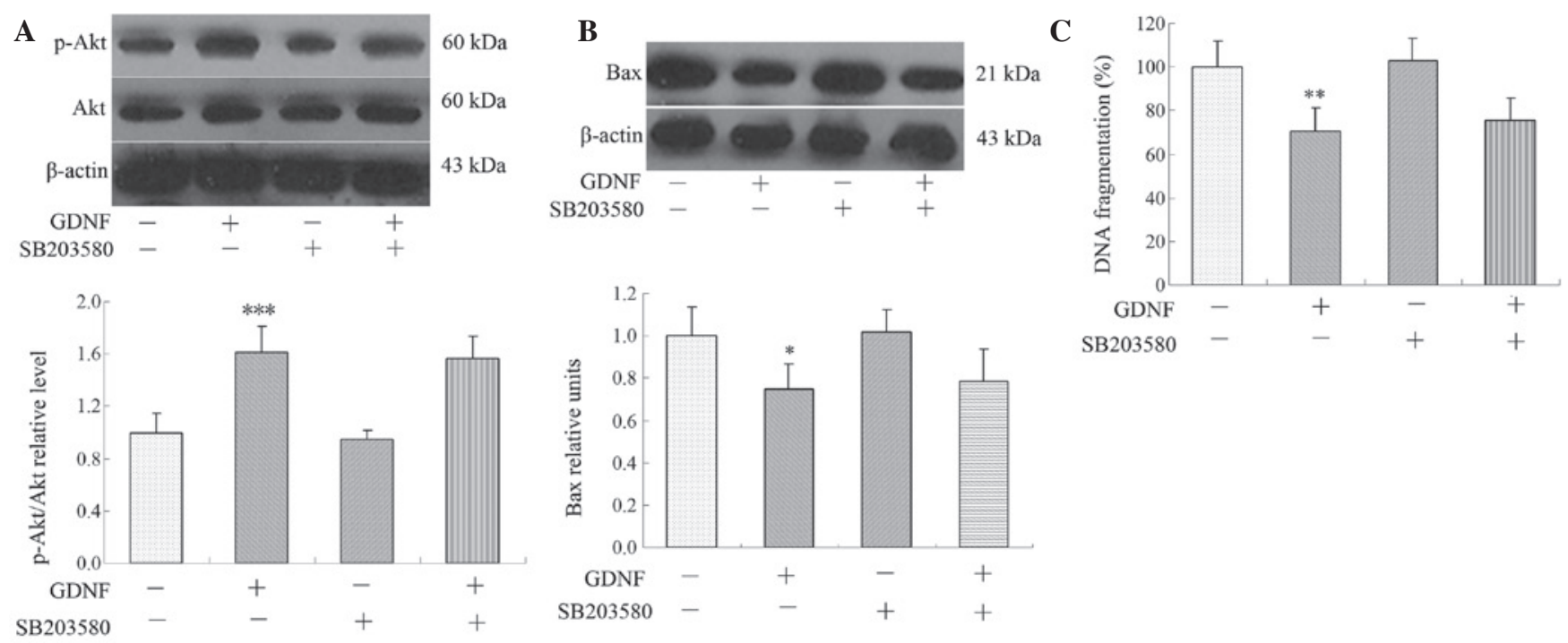

Figure 5. MAPK pathway was not involved in GDNF-mediated effects on the level of p-Akt/Akt, Bax and DNA fragmentation. P38 MAPK inhibitor, SB203580, did not abolish the GDNF-mediated (A) increase of p-Akt and the decrease of (B) Bax and (C) DNA fragmentation after treatment with (+) or without (-) GDNF, SB203580 or both. Data are expressed as the mean \pm standard error of the mean, $n=5$ for each group. ${ }^{*} \mathrm{P}<0.05,{ }^{* *} \mathrm{P}<0.01$ and ${ }^{* * * *} \mathrm{P}<0.001$ compared with the vehicle-treated control group. MAPK, mitogen-activated protein kinase; GDNF, glial cell line-derived neurotrophic factor.

\section{Discussion}

Neurons in the central nervous system are particularly vulnerable to hyperglycemia and GDNF has been shown to be protective against STZ-induced neural retina apoptosis in diabetic rats (12). Our previous study showed that exogenous GDNF decreased apoptosis in cultured Muller cells under high glucose conditions (21). The present study investigated the effect of supplementation of GDNF on apoptosis in the hippocampus and the mechanisms underlying this effect in rats with DE. STZ-induced diabetes caused notable apoptosis with markedly decreased levels of p-Akt/Akt in the brain. Treatment with GDNF significantly ameliorated apoptosis by upregulating p-Akt/Akt. The GDNF-induced decrease in the level of Bax and increase in the p-Akt/Akt level were associated with the PI3K/Akt pathway.

A single high dose injection of STZ can induce diabetes mellitus (27). This type of animal model has been widely used in the study of the pathophysiology of diabetes and its complications. The cognitive function of diabetic rats has been shown to be impaired in STZ-induced diabetes mellitus (3). Elevated blood glucose levels have been reported to cause degeneration of neurons in patients with diabetes (28). Type 2 diabetes has been found to induce changes in the cellular composition of the brain during aging (29). In the present study, it was demonstrated that Bax protein levels significantly increased (Fig. 3A and B) 2 months following induction of diabetes, which indicated that STZ induced apoptosis in DE.

It has been shown that the hippocampus is involved in learning/memory processes; and the neuronal cell apoptosis in the hippocampus has been shown to be associated with learning and memory or performance. The occurrence of neuropathy in diabetes, not only in diabetic patients but also in animal models, is well known. In the STZ model of diabetes, the persistence of increased apoptosis in the neural retina has been demonstrated (12). However, the evidence of neuronal apoptosis and its underlying mechanism in diabetes has not been fully elucidated. In the present study, it was demonstrated that hippocampus neuronal apoptosis is associated with diabetic neuropathy, as shown by the expression of Bax and by DNA fragmentation. A deficiency in the neurotrophic factor GDNF was also detected in the hippocampus. This is consistent with previous studies which reported that the levels of GDNF were downregulated in the colon of diabetic rats (30) and in the sciatic nerves of diabetic rats (31).

In vivo, administration of GDNF into the striatum or the lateral ventricle has been found to protect nigral dopaminergic neurons in a partial lesion model of Parkinson's disease (32). In addition, intracerebroventricular GDNF administration improved motor ability in bilaterally 6-hydroxydopamine lesioned rats (33). The above studies suggest that delivery of GDNF to cerebral ventricles may prove to be a possible method to treat DE.

The mechanisms involved in the effect of GDNF on neuronal apoptosis and survival have not been fully explored. GDNF has been shown to reduce apoptosis and enhance the survival of retinal ganglion cells (34). Previously it was demonstrated that exogenous GDNF not only decreased apoptosis under high glucose conditions but also accelerated the speed of synthesis of GDNF and GFR $\alpha 1$ proteins in Muller cells (21). In this study, it was observed that GDNF delivery significantly increased the level of Bax. The GDNF-mediated effect of preventing apoptosis was further confirmed by the decrease in DNA fragmentation in the hippocampus of rats with DE. GDNF signaling has been found to promote $\beta$-cell survival and improve glucose tolerance through the PI3K/Akt signaling pathway (35). In line with these observations, in the present study, GDNF enhanced the expression of p-Akt/Akt in the hippocampus and protected against apoptosis induced by diabetes mellitus. In another study, GDNF has also been shown to enhance human islet posttransplantation survival (20). 
Intracellular signaling pathways, including P38 MAPK and $\mathrm{PI}$ KK/Akt signaling pathways were involved in the regulation of cell survival. It was then investigated whether GDNF administration enhanced the activation of the PI3K/Akt pathway. GDNF-induced upregulation of p-Akt/Akt was reversed by treatment with the PI3K/Akt inhibitor Wortmannin, which is a specific inhibitor of PI3K in the nanomolar range (36) and $2.5 \mu \mathrm{M}$ Wortmannin has been shown to inhibit the expression of long-term potentiation in the dentate gyrus of rats (37). In addition, the PI3K/Akt inhibitor, Wortmannin also inhibited the GDNF-decrease of Bax and DNA fragmentation. However, treatment of diabetic rats with the p38 MAPK inhibitor SB203580 did not abolish the GDNF-mediated increase of p-Akt and the decrease of Bax and DNA fragmentation. PI3K/Akt is the only enzyme known to be inhibited by Wortmannin (38), which suggests that GDNF has the ability to reduce the level of Bax and the expression of DNA fragmentation is dependent on the activation of the PI3K/Akt pathway.

In conclusion, the present study demonstrates the involvement of GDNF loss in STZ-induced DE. It also demonstrated a protective effect of administration of GDNF, which was associated with its antiapoptotic effects. It was demonstrated that this function may be dependent on the activation of the PI3K/Akt pathway. These results provide evidence for the role of GDNF in preventing the progression of DE.

\section{Acknowledgements}

This study was supported partly by the key research areas of Xinxiang Medical University (grant no. ZD2011-28), the Science and Technology Project of Department of Education of Henan Province (grant no. 13A310862), the Doctoral Scientific Research Activation Foundation of Xinxiang Medical University, and the National Natural Science Foundation of China (grant no. 81301174).

\section{References}

1. Cui H, Lee JH, Kim JY, Koo BN and Lee JE: The neuroprotective effect of agmatine after focal cerebral ischemia in diabetic rats. J Neurosurg Anesthesiol 24: 39-50, 2012.

2. Kuhad A, Bishnoi M, Tiwari V and Chopra K: Suppression of NF-kappabeta signaling pathway by tocotrienol can prevent diabetes associated cognitive deficits. Pharmacol Biochem Behav 92: 251-259, 2009.

3. Zhou Y, Luo Y and Dai J: Axonal and dendritic changes are associated with diabetic encephalopathy in rats: An important risk factor for Alzheimer's disease. J Alzheimers Dis 34: 937-947, 2013.

4. Ola MS, Aleisa AM, Al-Rejaie SS, Abuohashish HM, Parmar MY, Alhomida AS and Ahmed MM: Flavonoid, morin inhibits oxidative stress, inflammation and enhances neurotrophic support in the brain of streptozotocin-induced diabetic rats. Neurol Sci 35: 1003-1008, 2014.

5. Liu J, Feng L, Ma D, Zhang M, Gu J, Wang S, Fu Q, Song Y, Lan Z, Qu R and Ma S: Neuroprotective effect of paeonol on cognition deficits of diabetic encephalopathy in streptozotocin-induced diabetic rat. Neurosci Lett 549: 63-68, 2013.

6. Mastrocola R, Restivo F, Vercellinatto I, Danni O, Brignardello E, Aragno $\mathrm{M}$ and Boccuzzi G: Oxidative and nitrosative stress in brain mitochondria of diabetic rats. J Endocrinol 187: 37-44, 2005.

7. Day JS, O'Neill E, Cawley C, Aretz NK, Kilroy D, Gibney SM, Harkin A and Connor TJ: Noradrenaline acting on astrocytic $\beta 2$-adrenoceptors induces neurite outgrowth in primary cortical neurons. Neuropharmacology 77: 234-248, 2014.
8. Saavedra A, Baltazar G and Duarte EP: Interleukin-1beta mediates GDNF up-regulation upon dopaminergic injury in ventral midbrain cell cultures. Neurobiol Dis 25: 92-104, 2007.

9. Shimizu F, Sano Y, Saito K, Abe MA, Maeda T, Haruki H and Kanda T: Pericyte-derived glial cell line-derived neurotrophic factor increase the expression of claudin-5 in the blood-brain barrier and the blood-nerve barrier. Neurochem Res 37: 401-409, 2012.

10. Zuo T, Qin JY, Chen J, Shi Z, Liu M, Gao X and Gao D: Involvement of $\mathrm{N}$-cadherin in the protective effect of glial cell line-derived neurotrophic factor on dopaminergic neuron damage. Int J Mol Med 31: 561-568, 2013.

11. Li F, Wang M, Zhu S, Li L, Xiong Y and Gao DS: The potential neuroprotection mechanism of GDNF in the 6-OHDAinduced cellular models of Parkinson's disease. Cell Mol Neurobiol 33: 907-919, 2013.

12. Wang L, Deng QQ, Wu XH, Yu J, Yang XL and Zhong YM: Upregulation of glutamate-aspartate transporter by glial cell line-derived neurotrophic factor ameliorates cell apoptosis in neural retina in streptozotocin-induced diabetic rats. CNS Neurosci Ther 19: 945-953, 2013.

13. Lin CY, Lin TY, Lee MC, Chen SC and Chang JS: Hyperglycemia: GDNF-EGR1 pathway target renal epithelial cell migration and apoptosis in diabetic renal embryopathy. PloS One 8: e56731, 2013.

14. Lui NP, Chen LW, Yung WH, Chan YS and Yung KK: Endogenous repair by the activation of cell survival signalling cascades during the early stages of rat Parkinsonism. PloS One 7: e51294, 2012.

15. Korsak K, Silva AT and Saffrey MJ: Differing effects of NT-3 and GDNF on dissociated enteric ganglion cells exposed to hydrogen peroxide in vitro. Neurosci lett 517: 102-106, 2012.

16. Mwangi SM, Nezami BG, Obukwelu B, Anitha M, Marri S, Fu P, Epperson MF, Le NA, Shanmugam M, Sitaraman SV, et $a l$ : Glial cell line-derived neurotrophic factor protects against high-fat diet-induced obesity. Am J Physiol Gastrointest Liver Physiol 306: G515-G525, 2014.

17. Takeda M, Takahashi M, Hara N and Matsumoto S: Glial cell line-derived neurotrophic factor modulates the excitability of nociceptive trigeminal ganglion neurons via a paracrine mechanism following inflammation. Brain Behav Immun 28: 100-107, 2013.

18. Uesaka T, Nagashimada M and Enomoto H: GDNF signaling levels control migration and neuronal differentiation of enteric ganglion precursors. J Neurosci 33: 16372-16382, 2013.

19. Shi JY, Liu GS, Liu LF, Kuo SM, Ton CH, Wen ZH, Tee R, Chen $\mathrm{CH}$, Huang HT, Chen CL, et al: Glial cell line-derived neurotrophic factor gene transfer exerts protective effect on axons in sciatic nerve following constriction-induced peripheral nerve injury. Hum Gene Ther 22: 721-731, 2011.

20. Mwangi SM, Usta Y, Shahnavaz N, Joseph I, Avila J, Cano J, Chetty VK, Larsen CP, Sitaraman SV and Srinivasan S: Glial cell line-derived neurotrophic factor enhances human islet posttransplantation survival. Transplantation 92: 745-751, 2011.

21. Zhu X, Sun Y, Wang Z, Cui W, Peng Y and Li R: Expression of glial cell line-derived neurotrophic factor and its receptors in cultured retinal müller cells under high glucose circumstance. Anat Rec (Hoboken) 295: 532-539, 2012.

22. Maekawa M, Takashima N, Matsumata M, Ikegami S, Kontani M, Hara Y, Kawashima H, Owada Y, Kiso Y, Yoshikawa T, et al: Arachidonic acid drives postnatal neurogenesis and elicits a beneficial effect on prepulse inhibition, a biological trait of psychiatric illnesses. PloS One 4: e5085, 2009.

23. Alvarez-Nölting R, Arnal E, Barcia JM, Miranda M and Romero FJ: Protection by DHA of early hippocampal changes in diabetes: Possible role of CREB and NF-kB. Neurochem Res 37: 105-115, 2012.

24. Xue HY, Lu YN, Fang XM, Xu YP, Gao GZ and Jin LJ: Neuroprotective properties of aucubin in diabetic rats and diabetic encephalopathy rats. Mol Biol Rep 39: 9311-9318, 2012.

25. Lapchak PA, Jiao S, Collins F and Miller PJ: Glial cell line-derived neurotrophic factor: Distribution and pharmacology in the rat following a bolus intraventricular injection. Brain Res 747: 92-102, 1997.

26. Gearhart DA, Middlemore ML and Terry AV: ELISA methods to measure cholinergic markers and nerve growth factor receptors in cortex, hippocampus, prefrontal cortex and basal forebrain from rat brain. J Neurosci Methods 150: 159-173, 2006. 
27. Kwon MH, Ryu JK, Kim WJ, Jin HR, Song KM, Kwon KD, Batbold D, Yin GN, Koh GY and Suh JK: Effect of intracavernous administration of angiopoietin-4 on erectile function in the streptozotocin-induced diabetic mouse. J Sex Med 10: 2912-2927, 2013.

28. Chandrasekharan B, Anitha M, Blatt R, Shahnavaz N, Kooby D, Staley C, Mwangi S, Jones DP, Sitaraman SV and Srinivasan S: Colonic motor dysfunction in human diabetes is associated with enteric neuronal loss and increased oxidative stress. Neurogastroenterol Motil 23: 131-138, e126, 2011.

29. Hussain S, Mansouri S, Sjoholm A, Patrone C and Darsalia V: Evidence for cortical neuronal loss in male type 2 diabetic goto-kakizaki rats. J Alzheimers Dis 41: 551-560, 2014.

30. Liu W, Yue W and Wu R: Effects of diabetes on expression of glial fibrillary acidic protein and neurotrophins in rat colon. Auton Neurosci 154: 79-83, 2010.

31. Liu GS, Shi JY, Lai CL, Hong YR, Shin SJ, Huang HT, Lam HC, Wen ZH, Hsu KS, Chen CH, et al: Peripheral gene transfer of glia cell-derived neurotrophic factor ameliorates neuropathic deficits in diabetic rats. Hum Gene Ther 20: 715-727, 2009.

32. Rosenblad C, Kirik D, Devaux B, Moffat B, Phillips HS and Björklund A: Protection and regeneration of nigral dopaminergic neurons by neurturin or GDNF in a partial lesion model of Parkinson's disease after administration into the striatum or the lateral ventricle. Eur J Neurosci 11: 1554-1566, 1999.
33. Bowenkamp KE, Lapchak PA, Hoffer BJ, Miller PJ and Bickford PC: Intracerebroventricular glial cell line-derived neurotrophic factor improves motor function and supports nigrostriatal dopamine neurons in bilaterally 6-hydroxydopamine lesioned rats. Exp Neurol 145: 104-117, 1997.

34. Koeberle PD and Bähr M: The upregulation of GLAST-1 is an indirect antiapoptotic mechanism of GDNF and neurturin in the adult CNS. Cell Death Differ 15: 471-483, 2008

35. Mwangi S, Anitha M, Mallikarjun C, Ding X, Hara M, Parsadanian A, Larsen CP, Thule P, Sitaraman SV, Anania F and Srinivasan S: Glial cell line-derived neurotrophic factor increases beta-cell mass and improves glucose tolerance. Gastroenterology 134: 727-737, 2008.

36. Divecha $\mathrm{N}$ and Irvine RF: Phospholipid signaling. Cell 80: 269-278, 1995

37. Kelly A and Lynch MA: Long-term potentiation in dentate gyrus of the rat is inhibited by the phosphoinositide 3-kinase inhibitor, wortmannin. Neuropharmacology 39: 643-651, 2000.

38. Niswender KD, Morrison CD, Clegg DJ, Olson R, Baskin DG, Myers MG Jr, Seeley RJ and Schwartz MW: Insulin activation of phosphatidylinositol 3-kinase in the hypothalamic arcuate nucleus: A key mediator of insulin-induced anorexia. Diabetes 52: 227-231, 2003. 